\title{
CLINICAL COMPARATIVE EVALUATION OF THE V-CUT PELVIC OSTECTOMY IN THE MANAGEMENT OF CANINE HIP DYSPLASIA
}

\author{
MUSTAFA VOLKAN YAPRAKCI ${ }^{1}$, MAREK GALANTY², AND KATARZYNA SIEWRUK ${ }^{3}$ \\ ${ }^{1}$ Department of Surgery and Clinical Sciences, Faculty of Veterinary Medicine, \\ University of Afyon Kocatepe, Afyonkarahisar, Turkey, mvyaprakci@aku.edu.tr \\ ${ }^{2}$ Department of Small Animal Diseases, Faculty of Veterinary Medicine, \\ Warsaw University of Life Sciences, 02-787 Warsaw, Poland \\ marek_galanty@sggw.pl \\ ${ }^{3}$ Department of Large Animal Diseases, Faculty of Veterinary Medicine, \\ Warsaw University of Life Sciences, 02-797 Warsaw, Poland \\ katarzyna_siewruk@sggw.pl
}

Received: October 26, 2012

Accepted: May 3, 2013

\begin{abstract}
The operational method (V-cut pelvic ostectomy) was applied on seven dogs. Pubic symphysis was cut in an inverted "V" fashion and a bone gap occurred between pelvic halves. The gap was reduced by contracting both sides of the pelvis. A new pubic symphysis developed. Results were evaluated with radiographs and different clinical and orthopedic tests. Radiographic measures between mutual parts of pelvic bone showed a marked increase in Norberg angles and diminishing in Bardens, Barlow, and Ortolani orthopedic tests after operations. Principal conclusion: V-cut pelvic ostectomy was found to be a successful operation technique in treatment of canine hip dysplasia.
\end{abstract}

Key words: dogs, canine hip dysplasia, ostectomy, juvenile pubic symphysiodesis.

Canine hip dysplasia (CHD) is one of the inherited diseases in dogs causing skeletal abnormality and joint incompatibility in hips. The disease is primarily defined as hip laxity in pathological aspect (16). The disease is progressive and leads to subluxation, damaged cartilaginous labrum in dorsal acetabulum rim (DAR), and osteoarthritis (OA) onwards (11). This degenerative joint disease (DJD) can be diagnosed by clinical, orthopaedic, and radiographical examinations $(1,7)$. Norberg angle is used to determine the radiographic joint laxity. Piermattei et al. (16) reported that the normal Norberg angles for Labrador Retrievers, Rottweilers, Golden Retrievers and German Shepperds were $99.9^{\circ}, 101.9^{\circ}, 92.6^{\circ}$, and $100.3^{\circ}$, respectively. Dueland et al. (7) found that juvenile pelvic symphisiodesis (JPS) dogs operated at earlier age appeared to have no progression in radiographic DJD according to their classification. The Orthopedic Foundation for Animals (OFA) classified the hips as excellent, good, and fair with borderline, mild, moderate, and severe for dysplasia on radiography (8). In addition, the Federation Cynologique Internationale (FCI) evaluated the disease as no sign, near normal type, mild, moderate, and severe hip dysplasia (21). Some tests such as Ortolani for hip subluxation, Bardens for hip translation, and Barlow for hip reduction signs are also well recognised in diagnosis of CHD $(2,5,9,22)$. Conservative and surgical methods are used for treatment of CHD $(4,9)$. Surgical techniques offer various kinds of solutions for the treatment. General surgical practices are changing from juvenile pubic symphysiodesis (jps), femoral neck lengthening (FNL), toggle pinning (TogP), sacrotuberous ligament transposition, triple pelvic osteotomy (TPO), dorsal acetabular rim arthroplasty (DARtrhoplasty), pectineal myectomy (pectinectomy), femoral head neck osteotomy (FHO), neurectomy to total hip replacement (THR) according to the age of patients and status of disease (16). The remodelling techniques changing the pelvic bone structure are more effective than the others (16). Regaining the decreased function of the uneven joint is the aim of these surgical methods (12). Although these techniques are crucial and beneficial for the treatment some detrimental complications may occur after operation $(6,10)$. Different researchers $(17,19)$ reported that these operations resulted in intensive pain and restriction of activity up to 3 months. A new V - cut pelvic ostectomy (VPO) technique for the treatment of hip dysplasia was developed in the study. One kind of JPS and TPO combination was applied on the pelvis of dogs. The study aimed to present the changes in preoperative and postoperative periods with the means of clinical, orthopaedic, and radiological methods. 


\section{Material and Methods}

The dogs (five females and two males) were selected from animals older than 4 months of age from large breeds. The mean body weight of the dogs was $28.8 \mathrm{~kg}$, and the mean age was 7 months. The group consisted of Labrador Retrievers (3), German Shepperds (2), American Staffordshire terrier (1), and New Foundland dog (1).

Clinical, orthopaedic, and radiographic examinations results were recorded for each case preand postoperatively. Patients' weight, gait quality, body conformation, concomitant diseases, hip dysplasia signs and their incidence were reported with clinical assessments. Hip laxity amount (Bardens test), hip reduction angles (Ortolani test), hip subluxation angles (Barlow test) were evaluated in orthopaedic examinations $(3,20)$.

Pre- and postoperative radiological inspections in every case were carried out on pelvic bones. Pelvic area was also segmented in radiographical images and every segment was marked with a letter representing the distances between anatomical landmarks in pelvis symmetrically. Radiological results were evaluated and classified according to DJD, OFA, FCI (8), and the Norberg's angle scales.

During the study X-ray examinations were performed for 6 weeks in all cases and 6 months in first two cases throughout the study. Diametric pelvic measurements used in this study were described by Yaprakc1 (23). Because of limited economic conditions of dog owners, tomographical methods could not be adopted into the study. Instead only radiographical methods were applied.

Dogs were anaesthetised according to total intravenous anaesthesia (TIVA) protocols with 6.6 $\mathrm{mg} / \mathrm{kg}$ of $1 \%$ propofol (Fresenius Kabi), in constant rate infusion $(2.20 \mathrm{mg} / \mathrm{kg} / \mathrm{h})$. A standard approach to the pubic symphysis was performed (15). Osteotomies were done by saving the underlying soft tissues. Cerclage wire was chosen as stabilisation type for the first two cases. Because of insufficient strength, a breakage occurred in the wire $(1.00 \mathrm{~mm}$ thick) after a number of trials in the second case. It was replaced by another type of thicker material $(1.40 \mathrm{~mm})$. Monofilament non-absorbable suture material (Monofilament Nylon or Hard Nylon Leader, Mason Tackle Co., Otisville) was chosen for fracture stabilisation due to material's higher strength in repetitive trials. The same bone stabilisation was applied in all of other cases.

Clindamycin hydrochloride (Klimicin, Lek, 20 $\mathrm{mg} / \mathrm{kg}$ ) was used for $5 \mathrm{~d}$ postoperatively for all cases. Patients did not show any pain or related clinical signs during recovery. Therefore, pain treatment was found unnecessary according to owner's debriefing.

Legs were hobbled together to restrict the hind legs from excess abduction until healing approved and power of adduction recovered (16). Owners were warned to avoid unrestrained activity for $10 \mathrm{~d}$. Skin sutures were removed 10 d after surgery. Rehabilitation was found unnecessary in recovery period.

\section{Results}

Operational procedure. In surgical procedure, none of the cases were exposed to any complications such as massive bleeding, nerve damage, puncturing of the colon, urethra or underlying soft tissues. An intraoperative implant failure occurred due to weakness of the material used in osteosynthesis in case 1. A thicker wire was then used instead. In other cases $(n=6)$, implant types were selected as nylon leader material. None of implant failures occurred afterwards. Long term radiographies verified healthy recovery in all cases. Case 7 developed skin wound complication due to owner's insufficient care. It was treated with antibiotic in recovery phase.

Radiologic inspections. Pelvic area was segmented with letters and represented in radiologic images (Figs 1, 2). Every letter in Figs 1 and 2 represents the distances between the landmarks of each symmetrical part in pelvis bones. The intervals among the symmetrical parts of pelvis were shown in Table 2. Percentage ratios of postoperative to preoperative measurements and postoperative segmental changes for 6 weeks in seven cases and 6 months in two cases were illustrated in Fig. 3. The highest reduction was observed in segment $\mathrm{H}$ at postoperative period. Segments D, E, F, G, and $\mathrm{H}$ in all cases were found to be underdeveloped. Similarly E, F, G, H, and J segment's development was also inhibited in two cases observed up to 6 months after operation.

Diametric results of radiographies of clinical cases are presented in Fig. 3.

Comparative radiographic classification results of clinical cases. Results of preoperative and postoperative radiographic and orthopaedic examinations (Ortolani, Bardens, and Barlow tests) are presented in Tables 1 and 2. The classification results of the cases in preoperative and postoperative period at 6 weeks were indicated in Table 1.

Five out of fourteen hip joint of seven cases converted to Ortolani negative by the week 6 . Case 4 had symmetrical change for both sides. The condition in case 1 was unchanged postoperatively. The indicator of joint laxity decreased or turned into negative in all cases with regards to Bardens test in postoperative period.

The hip reduction angles turned into negative at least unilaterally and mostly bilaterally in terms of Barlow test. Case 3 was seen to have unilateral increase in right side Barlow test angle. Overall Barlow test improvement was $50 \%$. 


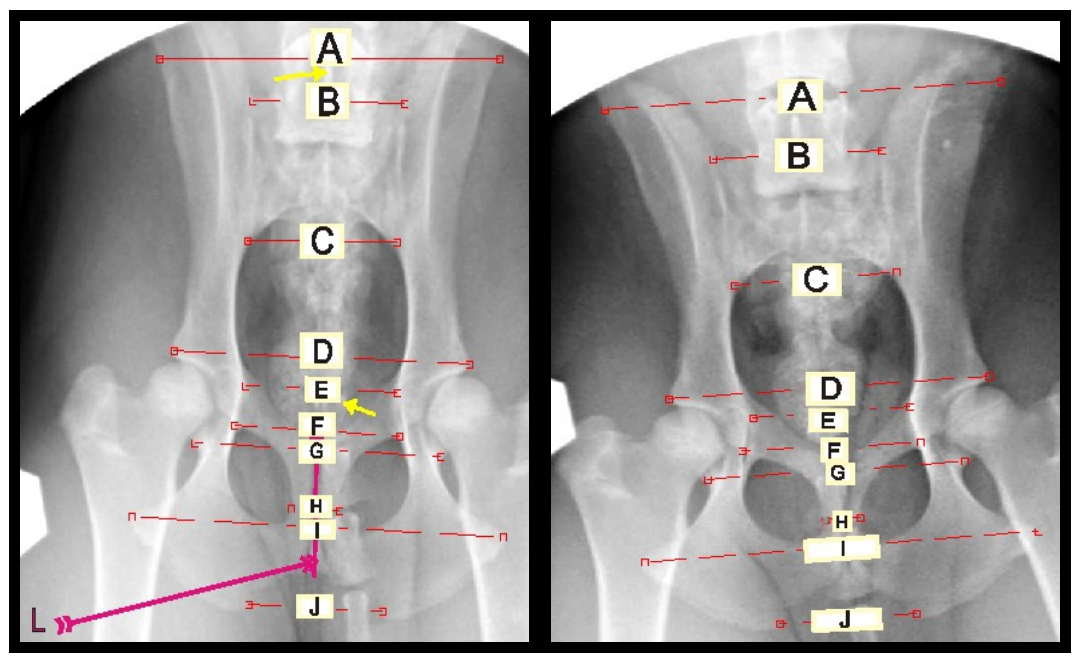

Figs 1, 2. Segmentation of pelvis in preoperative (left) and postoperative (right) phases

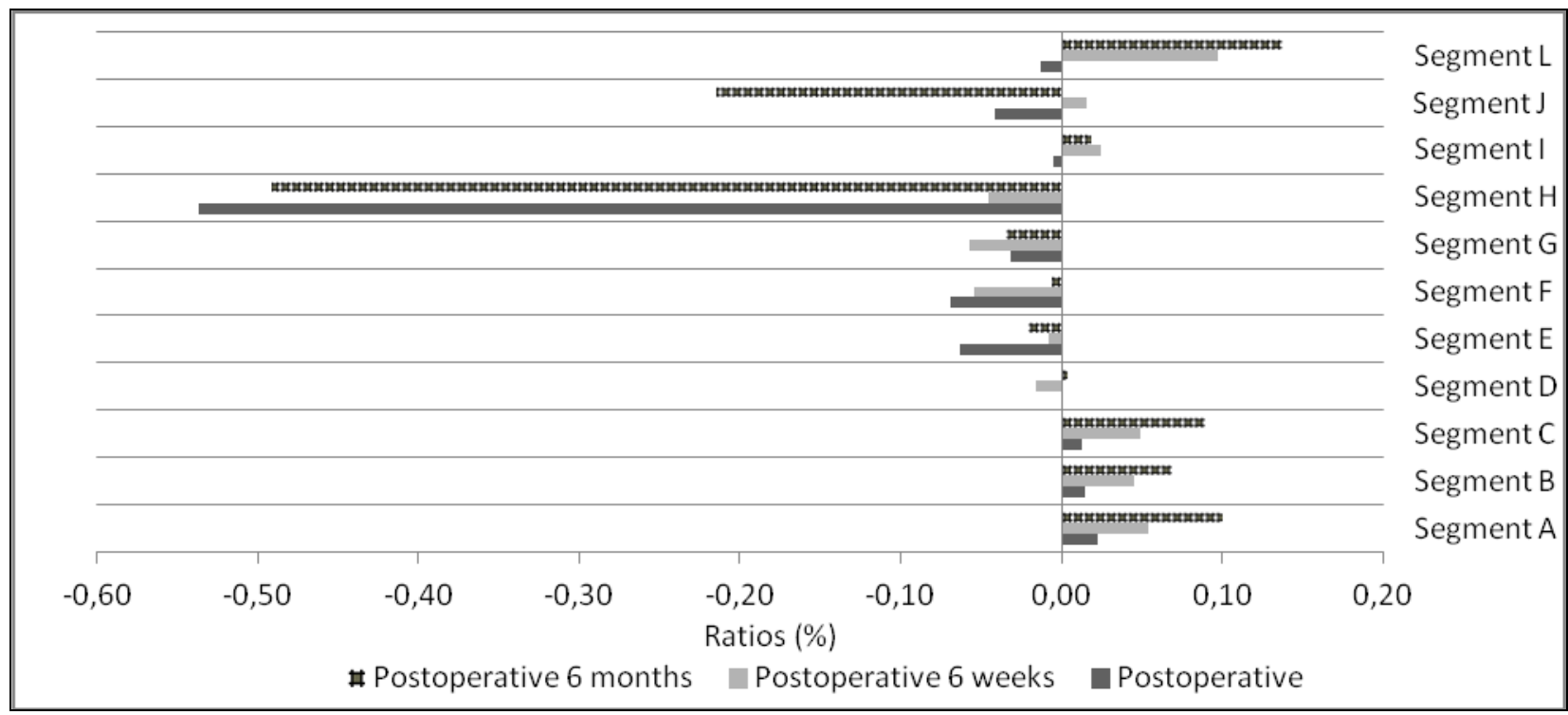

Fig. 3. Pelvic diameters of clinical cases $(\mathrm{cm})$

Table 1

Comparative radiographic examination results of clinical cases

\begin{tabular}{|c|c|c|c|c|c|c|c|c|c|c|c|c|c|c|c|}
\hline & & \multicolumn{2}{|c|}{ Case 1} & \multicolumn{2}{|c|}{ Case 2} & \multicolumn{2}{|c|}{ Case 3} & \multicolumn{2}{|c|}{ Case 4} & \multicolumn{2}{|c|}{ Case 5} & \multicolumn{2}{|c|}{ Case 6} & \multicolumn{2}{|c|}{ Case 7} \\
\hline & & $\mathrm{R}$ & $\mathrm{L}$ & $\mathrm{R}$ & $\mathrm{L}$ & $\mathrm{R}$ & $\mathrm{L}$ & $\mathrm{R}$ & $\mathrm{L}$ & $\mathrm{R}$ & $\mathrm{L}$ & $\mathrm{R}$ & $\mathrm{L}$ & $\mathrm{R}$ & $\mathrm{L}$ \\
\hline \multirow[t]{2}{*}{ DJD status } & preoperative & 3 & 3 & 2 & 2 & 3 & 4 & 3 & 3 & 2 & 2 & 4 & 3 & 1 & 2 \\
\hline & postoperative 6 weeks & 4 & 3 & 1 & 4 & 3 & 4 & 3 & 3 & 2 & 2 & 4 & 3 & 1 & 2 \\
\hline \multirow[t]{2}{*}{ OFA classification } & preoperative & Sev & Sev & Mil & $\mathrm{Sev}$ & Mod & Mod & Sev & Mod & Mod & Mil & Mil & Mil & Fai & Sev \\
\hline & postoperative 6 weeks & $\mathrm{Sev}$ & Sev & Mil & Sev & Mod & Mod & Sev & Mod & Mil & Mil & Bor & Bor & Go & Sev \\
\hline \multirow[t]{2}{*}{ FCI classification } & preoperative & $\mathrm{E}$ & $\mathrm{E}$ & $\mathrm{C}$ & $\mathrm{E}$ & $\mathrm{D}$ & $\mathrm{D}$ & $\mathrm{E}$ & $\mathrm{C}$ & $\mathrm{D}$ & $\mathrm{B}$ & $\mathrm{D}$ & $\mathrm{D}$ & $\mathrm{B}$ & $\mathrm{E}$ \\
\hline & $\overline{\text { postoperative } 6 \text { weeks }}$ & $\mathrm{E}$ & $\mathrm{E}$ & $\mathrm{C}$ & $\mathrm{C}$ & $\mathrm{D}$ & $\mathrm{D}$ & $\mathrm{E}$ & $\mathrm{C}$ & $\mathrm{B}$ & B & $\mathrm{C}$ & $\mathrm{C}$ & $\mathrm{B}$ & $\mathrm{E}$ \\
\hline \multirow[t]{2}{*}{ Norberg angle } & preoperative & 65 & 63 & 91 & 80 & 81 & 94 & 82 & 92 & 99 & 92 & 90 & 83 & 103 & 74 \\
\hline & postoperative $6 \mathrm{w}$ & 75 & 80 & 115 & 95 & 80 & 98 & 82 & 92 & 109 & 98 & 93 & 95 & 103 & 76 \\
\hline
\end{tabular}

R - right, L - left, exe - excellent, go - good, fai - fair, bor - borderline, mil - mild, mod - moderate, sev - severe 
Table 2

Comparative orthopaedic examination results of clinical cases

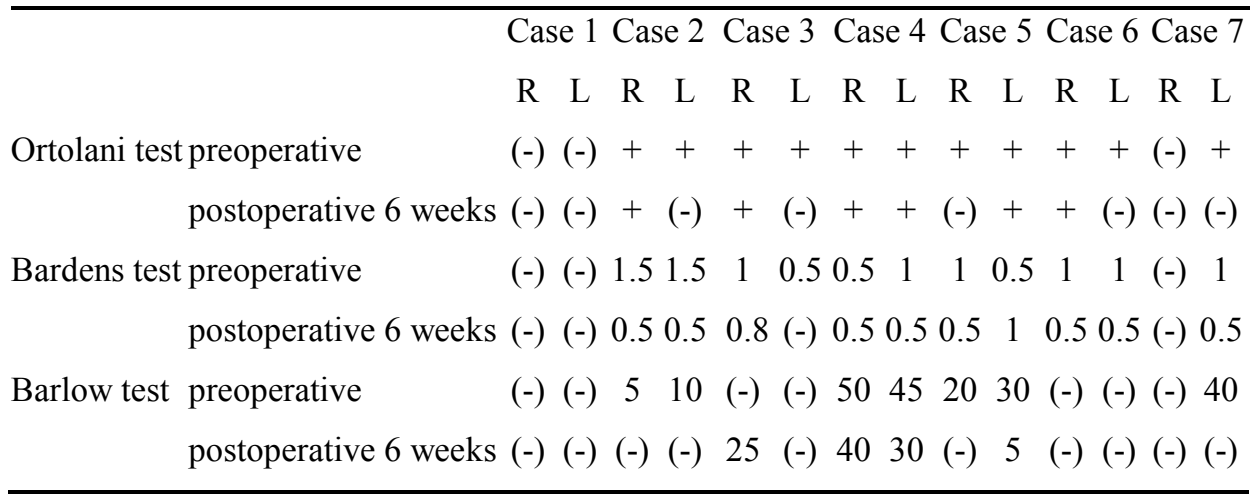

\section{Discussion}

The operation site has poor vascularity and neural network, and is suitable for easy surgical approach. Similar results were reported by Swainson et al. (18). In the study hip joint was turned into ventral direction during and after operation. This result is consonant with the finding of Dueland et al. (7). Hip joints were also turned in caudal direction distinctively. The mean DAR values in hip joints at $6^{\text {th }}$ week and $12^{\text {th }}$ month were found $7.4^{\circ}$ for all cases and $9.5^{\circ}$ for only first two cases, respectively. These values were lower than those of different researchers $(7,13)$ using JPS methods in juvenile dogs. These results suggested that the success rate of operation would decrease with the aging of patients. Similar results were reported by Dueland et al. (7) and Patricelli et al. (13). DAR values obtained in this study showed that the VPO technique assured relative success. According to some authors, JPS technique is less detrimental than others $(7,13,14)$. Likewise, only one case out of seven dogs developed postoperative wound complication in the study. Radiographic results suggested that there were no significant differences between preoperative and postoperative stages in 6 week data according to classification of DJD, OFA, and FCI. Similar results were reported by Dueland et al. (7), who used JPS method in dogs younger than 24 weeks of age. Mean Norberg angles in left and right hip raised to $93.9^{\circ}$ and $90.6^{\circ}$ postoperatively from $87.2^{\circ}$ and $82.6^{\circ}$ in preoperative phase. DJD degrees of hip joints were seen unchanged in $6^{\text {th }}$ week after operation. This finding was consonant with the reports of Dueland et al. (7).

A total of 11 positive Ortolani test findings were detected. Six (54\%) of them turned into negative until 6 weeks postoperatively. On the contrary, Dueland et al. (7) reported that seven (70\%) out of ten hip joints turned into negative in a 44 weeks period. This suggests that the effect of VPO occurs in a shorter time than JPS according to test results of Ortolani. Barlow tests also gave similar results except for only one case. This is consistent with the result of Dueland et al. (7).

As a result, three dimensional reconstructions can be obtained by VPO technique in dysplastic dogs. Differences between pre- and postoperative phases in left and right hand sides of hips were significant in only left side $(\mathrm{P}<0.05)$ suggesting that left hip joint was more affected by operation and showed quicker recovery than the right hip. VPO technique can be considered more effective than TPO and similar to JPS in the aspect of recovery period. VPO technique does not constitute an impediment for future operations in the same area. The technique is cheap and easy to implement. This is a successful method in the aspect of recovery period but further research with wider study groups would be useful for the improvement of the technique.

\section{References}

1. Adams W.M., Dueland R.T., Meinen J., O'Brien R.T., Giuliano E., Nordheim E.V.: Early detection of canine hip dysplasia: comparison of two palpation and five radiographic methods. J Am Anim Hosp Assoc 1998, 34, 339-347.

2. Chalman J., Butler H.: Coxofemoral joint laxity and the Ortolani sign. J Am Anim Hosp Assoc 1985, 21, 671676.

3. Corfield G., Read R., Eastley K., Richardson J., Robertson I., Day R.: Assessment of the hip reduction angle for predicting osteoarthritis of the hip in the Labrador Retriever. Aust Vet J 2007, 85, 212-216.

4. Curry S.L., Cogar S.M., Cook J.L.: Nonsteroidal antiinflammatory drugs: a review. J Am Anim Hosp Assoc 2005, 41, 298-309.

5. Dixon R.: Some experimental observations of the detection and demonstration of coxofemoral subluxation in the dog. Aust Vet Prac 1975, 55, 220-226.

6. Dudley R.M., Wilkens B.E.: Urethral obstruction as a complication of staged bilateral triple pelvic osteotomy. J Am Anim Hosp Assoc 2004, 40, 162-164.

7. Dueland R.T., Adams W.M., Fialkowski J.P., Patricelli A.J., Mathews K.G., Nordheim E.V.: Effects of pubic symphysiodesis in dysplastic puppies. Vet Surg 2001, 30, 201-217.

8. Flückiger M.: Scoring radiographs for canine hip dysplasia-the big three organisations in the world. Eur J Comp Anim Pract 2007, 17, 135-140.

9. Fry T., Clark D.: Canine hip dysplasia: clinical signs and physical diagnosis. Vet Clin North Am Small Anim Pract 1992, 22, 551-558.

10. Lee K.C.L., Kapatkin A.S.: Positive intraoperative cultures and canine total hip replacement: risk factors, 
periprosthetic infection, and surgical success. J Am Anim Hosp Assoc 2002, 38, 271-278.

11. Lieser B., Morphologische und biomechanische eigenschaften des hüftgelenks (Articulatio coxae) des hundes (Canis familiaris), Doctorate, InauguralDissertation, Universität München, 2003.

12. Olmstead M.L.: The canine cemented modular total hip prosthesis. J Am Anim Hosp Assoc 1995, 31, 109-124.

13. Patricelli A.J., Dueland R.T., Adams W.M., Fialkowski J.P., Linn K.A., Nordheim E.V.: Juvenile pubic symphysiodesis in dysplastic puppies at 15 and 20 weeks of age. Vet Surg 2002, 31, 435-444.

14. Patricelli A.J., Dueland R.T., Lu Y., Fialkowski J., Mathews K.G.: Canine pubic symphysiodesis: investigation of electrocautery dose response by histologic examination and temperature measurement. Vet Surg 2001, 30, 261-268.

15. Piermattei D., Johnson K.A.: Approach to the pubis and pelvic symphysis. In: An Atlas of Surgical Approaches to the Bones and Joints of the Dog and Cat, Saunders, Philadelpia 2004, pp. 323-325.

16. Piermattei D.L., Flo G.L., DeCamp C.E., Brinker W.O.: Hip dysplasia. In: Handbook of Small Animal Orthopedics and Fracture Repair. Elsevier Saunders, Philadelphia, 2006, pp. 475-511.

17. Rose B.W., Novo R.E., Olson E.J.: Osteosarcoma at the site of a triple pelvic osteotomy in a dog. J Am Anim Hosp Assoc 2005, 41, 327-331.
18. Swainson S.W., Conzemius M.G., Riedesel E.A., Smith G.K., Riley C.B.: Effect of pubic symphysiodesis on pelvic development in the skeletally immature Greyhound. Vet Surg 2000, 29, 178-190.

19. Terrell S.P., Chandra A.M.S., Pablo L.S., Lewis D.D.: Fatal intraoperative pulmonary fat embolism during cemented total hip arthroplasty in a dog. J Am Anim Hosp Assoc 2004, 40, 345-348.

20. Todhunter R.J., Bertram J.E., Smith S., Farese J.P., Williams A.J., Manocchia A., Erb H.N., Dykes N.L., Burton-Wurster N.I., Lust G.: Effect of dorsal hip loading, sedation, and general anesthesia on the dorsolateral subluxation score in dogs. Vet Surg 2003, 32, 196-205.

21. Verhoeven G., Coopman F., Duchateau L., Saunders J., Van Rijssen B., Van Bree H.: Interobserver agreement in the diagnosis of canine hip dysplasia using the standard ventrodorsal hip-extended radiographic method. J Small Anim Pract 2007, 48, 387-393.

22. Wright P., Mason T.: The usefulness of palpation of joint laxity in puppies as a predictor of hip dysplasia in a guide dog breeding programme. J Small Anim Pract 1977, 18, 513-522.

23. Yaprakc1 M.: V-cut pelvicosteotomy in the management of canine hip dysplasia cadaver study. Veteriner Cerrahi Dergisi 2009, 15, 10-14. 